\title{
Claves para leer a las asociaciones
}

\section{Keys to read associations}

JeAn-Louis, Laville (2015), Asociarse PARA EL BIEN COMÚN. TERCER SECTOR ECONOMÍA SOCIAL Y ECONOMÍA SOLIDARIA, ICARIA, BARCELONA, 2 I 4 PP., ISBN: 978-84-9888-686-3.

En los últimos años, el mapa de las asociaciones en el mundo ha cambiado significativamente: los grupos asociativos se multiplican, se desarrollan nuevas configuraciones y reglas para su integración, se ha ampliado su influencia y su importancia en el espacio social; simultáneamente han cambiado los patrones de su relación con el entorno, se establecieron nuevas formas de vinculación e intercambio con el Estado y con el mercado; también se transformaron sus estrategias operativas.

Los cambios - diversos en su origen, dimensiones y profundidad- se adjudican a múltiples factores entre los que se cuentan los efectos de las crisis económicas, el retraimiento del Estado en la procuración del bienestar, la democratización de las sociedades y la búsqueda de alternativas a la persistencia de problemas como la pobreza y la exclusión.

Los procesos mencionados -que han incidido en la transformación de las concepciones del espacio y de la acción pública, al tiempo que han transformado también los modos de pensar lo privado- incurren también en la modificación de las nociones de público y privado, las cuales, además, son insuficientes para explicar lo que acontece en la esfera social, puntuada por nuevas formas de gestión y prestación de servicios de interés público que no encuentran cabida en la esfera estatal ni en la mercantil. Estos procesos y modificaciones repercuten, asimismo, en la transformación de la visión sociológica, económica y política sobre el sector asociativo, que impele a una más amplia participación de los actores civiles en la vida pública y en la atención a los problemas sociales.

En otra vertiente, los cambios en el sector asociativo han interactuado con las transformaciones del corpus de conocimiento sobre la naturaleza y formas que asume la sociedad civil, y con los marcos teórico-metodológicos que buscan explicar las relaciones sociales y orientan la investigación académica en ese campo disciplinario; las influencias multidireccionales de esa dinámica han ido generando un conjunto de categorías y posiciones a través de los cuales la investigación académica sociológica y política explica los fenómenos sociales. Los cambios en este ámbito han dado lugar a nuevas nociones y significados acerca de la naturaleza y razón de ser de los procesos asociativos y han configurado un lenguaje propio a 
través del cual se expresan los principios, valores, hallazgos y avances en el conocimiento sobre las asociaciones.

En el caso de México, entre las transformaciones que marcan la transición del siglo XX al siglo XXI se encuentra el posicionamiento del sector asociativo como un sector prominente -particularmente en las esferas de provisión de bienestar, procuración de los derechos humanos, democracia y desarrollo sustentable- a través de asociaciones que participan en ámbitos como el comercio justo, las empresas sociales, el emprendedurismo, la participación ciudadana y el desarrollo comunitario. En ese desenvolvimiento, las instituciones sin fines de lucro -sector del cual forman parte las asociaciones prestadoras de servicios sociales- representan una parte significativa del Producto Interno Bruto (PIB) nacional, por lo que se puede decir que su impacto en la economía de la nación es también notable. ${ }^{1}$

En la dinámica móvil y cambiante del universo asociativo, el estudio de las asociaciones requiere de nuevas claves que permitan leer estos cambios; el libro de Jean-Louis Laville, Asociarse para el bien común. Tercer sector economía social y economía solidaria, es una contribución importante para los investigadores del área de las disciplinas sociales, ya que su propuesta permite replantear la forma de estudiar la intervención y el papel de las asociaciones en varios sentidos: a) los problemas actuales demandan encontrar solución a la fragilidad de la democracia frente a una economía sin límites, b) las asociaciones desempeñan un papel vital para la sociedad, $c$ ) se requiere una nueva lectura del asociacionismo, $d$ ) es indispensable replantear el papel de la economía en la sociedad.

Para destacar sus aportaciones vale la pena tener en cuenta que el autor ha sido impulsor de una corriente alternativa de conocimiento sobre el papel de la economía en las sociedades que pone en primer plano la necesidad de promover la existencia de una economía plural, particularmente en los campos de la economía social y la economía solidaria; con esa orientación ha construido conceptos y análisis que actualmente constituyen un marco de referencia para el trazo de una visión distinta a la de la economía racionalista y de mercado, que estima la razón de ser de las asociaciones como resultado del impulso de consecución del mayor beneficio individual. ${ }^{2}$

Los ángulos de reflexión de Laville desplazan y contrastan esa visión a partir del reconocimiento de la existencia de relaciones económicas en

${ }^{1}$ Datos del Informe 2014 de la Cuenta Satélite de las Instituciones Sin Fines de Lucro, publicado por el Instituto Nacional de Geografía y Estadística (Inegi), indican que el PIB generado por las organizaciones no lucrativas alcanzó 490 mil 900 millones de pesos corrientes en 2014. Esta cantidad representó el 3.0 del PIB total de la economía del país (Inegi, 2016).

${ }^{2}$ En esa perspectiva los fenómenos económicos pueden ser explicados como la agregación de las conductas racionales de los individuos. 
las que la ganancia no es el motor principal de la acción asociativa; se trata de una reflexión alternativa indispensable para ampliar el análisis de las asociaciones en su naturaleza de provisoras de bienes a través de arreglos económicos cooperativos orientados al beneficio común. ${ }^{3}$ Asimismo, habría que considerar que una buena parte de los estudios que este autor ha realizado se han publicado en idioma francés y que solamente algunos han sido traducidos al inglés o al español, por lo que no son fácilmente accesibles al público de habla hispana.

Abonan también a su relevancia, la reflexión conceptual y metodológica que articula el texto, útil para los investigadores que tienen como campo disciplinario a la sociedad civil, ya que es fundamental para la investigación poder integrar categorías y cuerpos de literatura básica que posibiliten discutir, debatir y validar sus resultados.

$\mathrm{Al}$ igual que en otros campos temáticos, en el estudio de las asociaciones ha hecho falta desarrollar capacidades para estructurar un lenguaje propio y de significados compartidos; la heterogeneidad de los estudios, la dispersión temática y las evidentes dificultades para ir constituyendo un corpus de metodologías aceptadas por la comunidad científica, como medios especializados para estudiar las organizaciones civiles y no lucrativas, se han convertido en obstáculos para la consolidación de la disciplina.

En el mismo sentido, es pertinente llamar la atención del lector sobre el hecho de que esta obra forma parte de un conjunto integral de numerosos libros y artículos en los que Laville ha examinado el asociacionismo y la economía solidaria desde distintos enfoques y con diferentes interrogantes, entre los que se pueden mencionar, a manera de ejemplo, la forma en la cual la sociedad civil, el tercer sector y las empresas sociales construyen alternativas de gobernancia y democracia (Laville et al., 2015); la parte importante que representa el sector asociativo en la acción pública a través de la producción de bienes y servicios en la generación de bienestar (Laville y Salmon, 2015); la influencia de la corriente gerencial o del New Public Management sobre el asociacionismo -que impone nuevas presiones a las asociaciones con una visión que otorga prioridad a la eficacia y la eficiencia, más que los fines de los grupos asociativos y a su misión social- escenario en el que han tenido que mejorar su eficacia y su eficiencia, demostrar competencias y cubrir requerimientos técnicos; las relaciones que existen entre el resurgimiento de una economía de base

${ }^{3}$ Laville es el coordinador europeo del Instituto Karl Polinia de Economía política, es profesor investigador del Conservatoire National des Arts et Métiers de Paris. Sus estudios aportan al análisis de los grupos civiles como estructuras de gobernanza, así como al replanteamiento de las asociaciones como actores que, como una derivación de las transformaciones en las esferas estatal, mercantil, familiar y solidaria forman parte sustancial de la acción pública; asimismo destaca su papel en el análisis de los distintos aspectos que dan sustento a las tesis de factibilidad y promoción de una economía solidaria (Laville et al., 2015; Laville y Salmon, 2015). 
solidaria y civil, con la evolución de nuevas formas de compromiso cívico y con los cambios estructurales en las actividades productivas y de prestación de servicios (Laville, 2003); estudios que en su conjunto conforman una línea de investigación que asume también, ciertamente, un carácter promocional y propositivo para la exploración de una visión alternativa de la economía que responda mejor a las necesidades de la sociedad.

En ese sentido, el libro se teje como un análisis conceptual que ayuda a distinguir, redefinir y ubicar a los grupos asociativos dentro de los campos del tercer sector, la economía social, la economía popular y la economía solidaria, conceptos que, con frecuencia, han sido vistos como intercambiables y que en realidad son distintos en su origen, características y fines.

El prólogo, escrito por Jordi Estivill, contribuye en buena medida a clarificar la posición de Laville en el espectro de las perspectivas contemporáneas para el estudio de las organizaciones y asociaciones civiles; el análisis con el que se presenta la obra destaca la visión histórica y conceptual sobre el asociacionismo y ayuda explicar las razones por las que se concede a éste un papel político principal en la transformación de las relaciones sociales y económicas; Estivill -quien es también un investigador reconocido en el estudio de la sociedad civil- revisa críticamente la posición del autor en su confrontación con los debates conceptuales y metodológicos vigentes en la escala internacional; su visión sobre el desarrollo de los paradigmas de la economía solidaria en Europa, Estados Unidos y América Latina, permite ubicar y distinguir el desarrollo de la economía popular en Chile y Brasil, la socio-economía en Uruguay, así como la economía del trabajo en Argentina.

Se puede decir que los propósitos del libro se aglutinan para sustentar una visión del asociacionismo concebido como un proyecto transformador de las relaciones sociales, las cuales se consideran impregnadas actualmente por el espíritu del neoliberalismo y del capitalismo depredador; se construye al asociacionismo como la acción colectiva y voluntaria de ciudadanos libres e iguales que se unen en aras de un bien común.

El punto de partida se fija al reexaminar el devenir histórico de las distintas corrientes que articulan la acción asociativa. Al perfilar los orígenes distintos de las corrientes que hoy configuran las vertientes del tercer sector, de la economía social y de la economía solidaria, se teje una interpretación sobre la mayor vinculación de la perspectiva del tercer sector con el papel complementario que cumplen las asociaciones en una economía de mercado; en tanto que en la economía social se concede un papel más importante a la configuración de un patrimonio colectivo en relación a la que se otorga al afán de lucro, el patrimonio se construye a partir de las asociaciones cooperativas y mutualistas y los beneficios se redistribuyen entre sus miembros; la economía solidaria, a su vez, plantea 
considerar a la economía como un medio al servicio de las finalidades humanas dentro de marcos institucionales que integran lógicas distintas a los móviles meramente económicos, la consecución y el impacto de sus ganancias se extienden más allá de sus miembros. Así, las particularidades del devenir histórico son la base para la parte sustantiva del texto, consistente en definir los conceptos que comúnmente son utilizados como categorías, rubros comprehensivos o identificadores en el conjunto amplio y diverso del estudio de las asociaciones.

En función de estos propósitos se consideran varios ejes que, a modo de capítulos, explican, primero, la construcción de las diferentes visiones sobre el asociacionismo en el mundo social, sus giros y derivaciones en distintos ámbitos nacionales; los desplazamientos son explicados en función de una línea de tensión que se mueve entre los polos de poder de la democracia y la hegemonía del capitalismo (capítulos I y II). El eje explicativo de las diferencias imbuidas en los arreglos institucionales que guían la acción de las asociaciones se ubica en su vinculación con los distintos ámbitos de poder.

El segundo eje -condensado mayormente en el capítulo III: "Los retos del debate contemporáneo"- hace una interpretación de las metamorfosis del asociacionismo, relacionándolas con los enfoques teóricos que han construido diferentes perspectivas sobre la naturaleza de la acción e identifica las esferas predominantes en las que se mueven, así como las características que asumen los vínculos de cada una de las corrientes.

El tercer eje, (capítulos IV y V) está dirigido a definir conceptualmente los ámbitos de la economía social y de la economía solidaria en su relaciones y diferencias con la visión del tercer sector.

Los ejes convergen en la propuesta de un movimiento que considere revisar el papel de las asociaciones como la base de la transformación social y política en sociedades desiguales, laceradas por el capitalismo desregulado y los desequilibrios provocados por la globalización; esa corriente alternativa se apoya en la economía solidaria como una opción viable en el marco de los avances democráticos que impulsan un nuevo compromiso cívico y un proyecto político.

Bajo la mirada, un tanto idealizada, desde la cual sería factible pensar el proyecto transformador, el asociacionismo y sus actores son quienes tienen las potencialidades para articular las esferas políticas y económicas que se traducen en las ideas de democracia y economía plurales; igualmente se considera que es la única opción capaz de dar la batalla a la degradación social y ecológica generada por el modelo desarrollo del capitalismo globalizador (Laville, 2015: 184-185).

La ausencia de una mirada crítica para la posición que condensa la tesis central del libro es, tal vez, la mayor objeción a sus planteamientos, 
puesto que no se contempla la situación de desventaja desde la cual se pretende lograr la transformación social. La pretensión de transformar el capitalismo desde el asociacionismo puede sonar no solamente utópica, sino sesgada en un análisis que de cualquier modo es muy completo y consistente.

Finalmente, otra de las razones para tener este texto en el horizonte de los libros sobre sociedad civil radica en las necesidades de la investigación académica de avanzar en la construcción de un cuerpo conceptual o de literatura básica que permita un lenguaje propio de significados compartidos que abone a la consolidación del conocimiento; al respecto son esclarecedores los comentarios de Estivill que advierten sobre la forma en la que se ha difundido mayormente la terminología globalizadora de los organismos internacionales, en detrimento de la que concierne a la economía social y a la economía solidaria, observa que en América Latina hay una menor cristalización terminológica que en Europa, debilidad que da lugar a que conceptos muy distintos en su origen y significado se utilicen como sinónimos o sirvan para caracterizar realidades semejantes o, a veces, incluso bastante alejadas (Estivill, 2015: 20).

En suma, el recorrido por los hallazgos y vericuetos de este itinerario conceptual es una contribución al estudio del lenguaje que permea el campo del conocimiento sociológico y político de las organizaciones civiles, sin dejar de tener a la vista que el ángulo desde el cual se traza es el de una economía plural y alternativa, ámbito que se encuentra todavía en construcción y debate.

\section{Fuentes consultadas}

Estivill, Jordi (2015), "Prólogo. El asociacionismo vector de la Economía Solidaria”, en Jean-Louis Laville, Asociarse para el bien común. Tercer sector economía social y economía solidaria, Icaria, Barcelona, pp. 7-31.

Inegi (Instituto Nacional de Geografía y Estadística) (2016), "Cuenta satélite de las instituciones sin fines de lucro, Informe 2014", Inegi, <http://www.inegi.org.mx/est/contenidos/proyectos/cn/ isfl/>, 8 de agosto de 2016 .

Laville Jean-Louis (2015), Asociarse para el bien común. Tercer sector economía social y economía solidaria, Icaria, Barcelona. 
Laville, Jean-Louis, Denis R. Young y Philippe Eynaud (2015), The third sector and social Enterprise. Governance and democracy, Routlegdge, Nueva York.

Laville, Jean-Louis y Anne Salmon (2015), Associations et action publique, Étions Desclée de Brouwer, Paris.

Laville Jean-Louis (2003), "A new european socioeconomic perspective", Review of Social Economy, LXI (3), Taylor \& Francis online, pp. 389-405.

Recibido: 11 de mayo de 2016. Aceptado: 15 de mayo 2016.

Gloria Jovita Guadarrama Sánchez El Colegio Mexiquense, A. C. Correo-e: gguadarr@cmq.edu.mx

Gloria Jovita Guadarrama Sánchez. Mexicana. Es doctora en ciencias políticas y sociales por la UNAM y miembro del Sistema Nacional de Investigadores, nivel II. Actualmente es profesora investigadora en $\mathrm{El}$ Colegio Mexiquense, A. C., institución en la cual también se ha desempeñado como docente, coordinadora de investigación académica y miembro de la Junta de Gobierno. Sus líneas actuales de investigación son: instituciones, políticas públicas, asistencia social, sociedad civil y tercer sector. Por el conjunto de su obra publicada y su experiencia en la investigación social, en 2012, recibió el Premio Estatal al Altruismo que otorga el Gobierno del Estado de México en su modalidad de Investigación Social Asistencial. Asimismo, le fue otorgada la Presea Estado de México de Pedagogía y Docencia, 2014. Es autora de varios libros, capítulos y artículos en revistas científicas enfocados en políticas públicas. Actualmente, es coordinadora del Seminario "Instituciones sociedad civil y políticas públicas" y de la "Red de estudios sobre gestión municipal”. Es miembro de la Red de Estudios para el Desempeño Asociativo de la UNAM e integrante del Consejo Académico de El Colegio Mexiquense, A. C. Entre sus publicaciones recientes se cuentan: La agenda de género en municipios mexiquenses. La reconfiguración local de la agenda nacional, El Colegio Mexiquense A. C., Zinacantepec, 53 pp. (2012); Políticas educativas y agenda de gobierno. Equidad y calidad pendientes, El Colegio Mexiquense A. C., Zinacantepec, 186 pp. (2012); Un lugar indefinido. El género en la agenda municipal; la reconstrucción local de la politica 
nacional en el Estado de México, El Colegio Mexiquense A. C., Zinacantepec, 261 pp. (2015). Fue co-coordinadora del libro El auxilio en las ciudades: instituciones, actores y modelos de protección social en Argentina $y$ México siglos XIX y XX, El Colegio Mexiquense A. C.-Centro de Estudios Históricos. Carlos S. A. Segreti, Zinacantepec, 503 pp. (2015). En su libro Entre la caridad y el derecho: Un estudio sobre el agotamiento del modelo nacional de asistencia social, Colegio Mexiquense, A. C.-Consejo Estatal de Población, Zinacantepec, 265 pp. (2001), hace un examen profundo de la asistencia social en nuestro país y particularmente en el Estado de México. 